Was ist neu in der medikamen-
tösen Therapie?
Wir halten Sie auf dem
Laufenden mit Berichten von
Kongressen und Symposien der
pharmazeutischen Industrie.

\title{
Alzheimer-Demenz
}

\section{Günstige Wirkung von Ginkgo biloba und hyperbarem Sauerstoff}

- Chinesische Wissenschaftler um Dr. Xiao Quiang Tian, Southeast University in Nan Jing, Provinz Jiang Su, China, haben Mäusen $A \beta$-Peptide in den rechten und linken Hippocampus injiziert, um ein Tiermodell für die Alzheimer-Erkrankung zu erzeugen, und den Krankheitsverlauf mit unbehandelten Mäusen verglichen. Einige Alzheimer-Mäuse wurden mit einer hyperbaren Sauerstofftherapie behandelt, einige mit dem Ginkgo-biloba-Extrakt EGb761 ${ }^{\circledR}$ (in Deutschland Tebonin ${ }^{\circledast}$ ) sowie eine weitere Gruppe mit der Kombination aus beidem.

\section{Zellapoptose wird unterdrückt}

Die A $\beta$-Peptid-Injektion erzeugte Störungen des räumlichen Lernens und $\mathrm{Ge}$ dächtnisses, was auf neuronale Apoptosen im Hippocampus zurückgeführt wurde. Im
Morris-Wasserlabyrinth waren die Alzheimer-Mäuse schlechter in der Lage, die unter Wasser befindliche Plattform zu finden als gesunde Mäuse.

Eine Behandlung mit Ginkgo biloba und/oder mit hyperbarem Sauerstoff reduzierten die Defizite der Alzheimer-Mäuse. Dabei erwies sich die Kombination aus beiden Behandlungen als vergleichsweise effektiver - nicht nur, was das Verhalten im Wasserlabyrinth anging.

Auch weitere Laborresultate sprechen für einen therapeutischen Effekt der Mono- wie der Kombitherapien. So zeigten die post mortem untersuchten Gehirne signifikant weniger Apoptose-Merkmale. Dieser Befund stimmte überein mit der Messung mehrerer Marker, die den Zellgewebeschaden bei Alzheimer-Demenz cha-

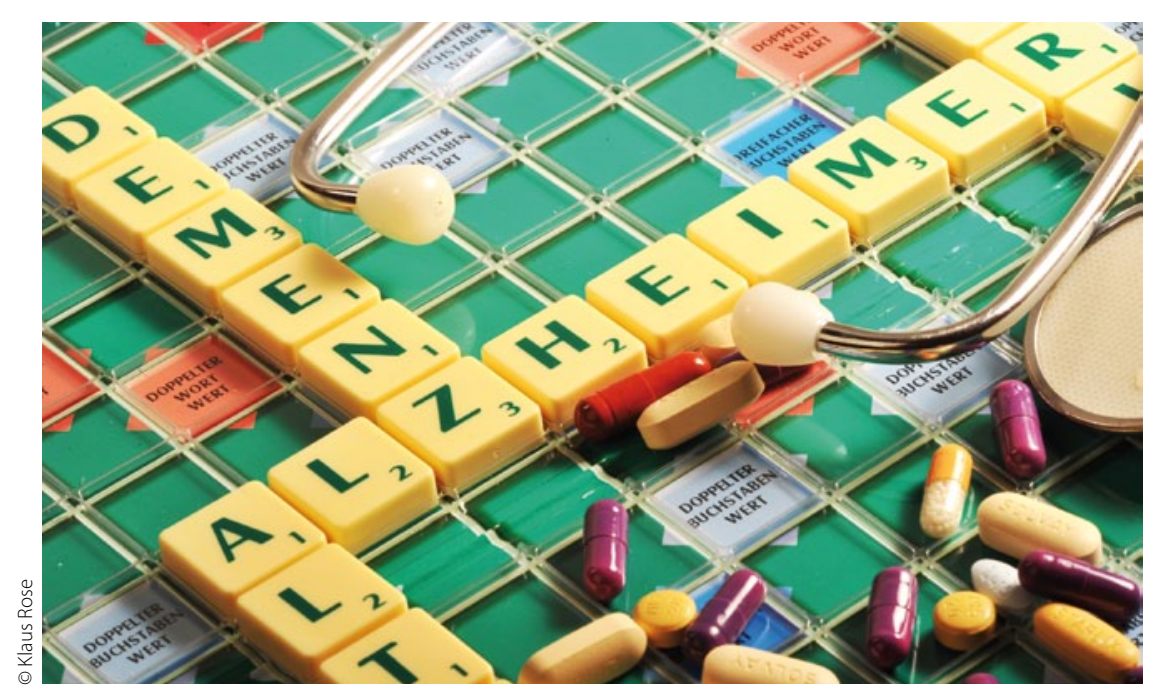

Die Alzheimer-Demenz ist nicht heilbar, aber ihre Progression lässt sich verlangsamen.

\section{Kurz notiert}

Patientenaufklärung $>$ Infekte der oberen und unteren Atemwege sind ein häufiger Grund für einen Arztbesuch. Um den Patienten die Funktionsweise der Lunge, des Innenohres und den Entstehungsprozess eines Infektes in den Atemwegen besser erklären zu können, bietet Pohl-Boskamp die Aufsteller „Ein Blick ins Innere" an. Alle Organe der oberen und unteren Atemwege sind anschaulich dargestellt. So können Ärzte u. a. erklären, wie GeloMyrtol ${ }^{\circledR}$ forte das zähe Sekret in den Atemwegen löst, die mukoziliäre Clearance steigert und mit antientzündlichen und antibakteriellen Zusatzeffekten den Heilungsprozess unterstützt. Zu bestellen per E-Mail: anforderung@pohlboskamp.de

Pohl Boskamp

rakterisieren. Auch die Expression von Regulator-Genen der Apoptose war durch das Verabreichen von Ginkgo biloba und hyperbarem Sauerstoff antiapoptotisch beeinflusst worden.

Die antioxidativen Effekte des Ginkgobiloba-Extrakts ergeben sich aus sinkenden reaktiven Sauerstoffspezies unter der Therapie. Die Lipidperoxidation von Zellmembranen wird unterdrückt und die Aktivität antioxidativer Enzyme wird gesteigert. Auch für die hyperbare Sauerstofftherapie haben Studien gezeigt, dass die Bildung freier Radikale gehemmt wird. Antioxidativ wirkende Enzyme wie SuperoxidDismutase und Gluatathion-Peroxidase werden aktiviert. Und die Integrität der für oxidativen Stress besonders vulnerablen Mitochondrien wird erhalten.

- Thomas Meißner, Erfurt

Quelle: Behavioural Brain Research 2013;242:1-8 